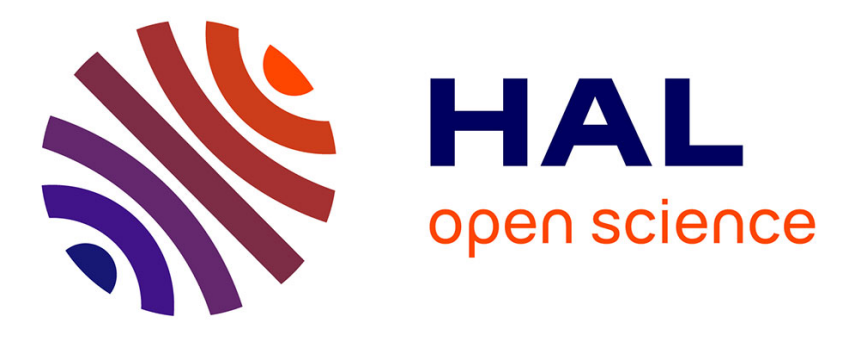

\title{
Polyelectrolyte Multilayers and Degradable Polymer Layers as Multicompartment Films
}

\author{
Juan Mendez Garza, Nadia Jessel, Guy Ladam, Valérie Dupray, Sylvaine
}

Muller, Jean-Francois Stoltz, Pierre Schaaf, Jean-Claude Voegel, Philippe Lavalle

\section{To cite this version:}

Juan Mendez Garza, Nadia Jessel, Guy Ladam, Valérie Dupray, Sylvaine Muller, et al.. Polyelectrolyte Multilayers and Degradable Polymer Layers as Multicompartment Films. Langmuir, 2005, 21 (26), pp.12372-12377. 10.1021/la051465b . hal-02337152

\section{HAL Id: hal-02337152 https://hal.science/hal-02337152}

Submitted on 29 Oct 2019

HAL is a multi-disciplinary open access archive for the deposit and dissemination of scientific research documents, whether they are published or not. The documents may come from teaching and research institutions in France or abroad, or from public or private research centers.
L'archive ouverte pluridisciplinaire HAL, est destinée au dépôt et à la diffusion de documents scientifiques de niveau recherche, publiés ou non, émanant des établissements d'enseignement et de recherche français ou étrangers, des laboratoires publics ou privés. 


\title{
Polyelectrolyte Multilayers and Degradable Polymer Layers as Multicompartment Films
}

\author{
Juan Méndez Garza,,,,,,$+ \|$ Nadia Jessel, ${ }^{\dagger, \dagger}$ Guy Ladam, ${ }^{\perp}$ Valérie Dupray, ${ }^{\perp}$ \\ Sylvaine Muller,, ,॥ Jean-François Stoltz, ${ }^{\S}, \|$ Pierre Schaaf,\# \\ Jean-Claude Voegel, ${ }^{\dagger, \ddagger}$ and Philippe Lavalle ${ }^{*, \dagger, \dagger}$

\begin{abstract}
INSERM U595, Strasbourg, F-67085 France, Faculté de Chirurgie Dentaire, Université Louis Pasteur, Strasbourg, F-67085 France, Mécanique et Ingénierie Cellulaire et Tissulaire-LEMTA, CNRS, UMR7563, Vandouvre-les-Nnacy, F-54500 France, Faculté de Médecine, Université Henri Pointcaré, Vandoeuvre-les-Nancy, F-54500 France, Laboratoire de Biophysique et Biomatériaux, Université d'Evreux, Evreux, F-27002 France, and CNRS, UPR22, Institut Charles Sadron, Strasbourg, F-67083 France
\end{abstract}

Received June 3, 2005. In Final Form: September 21, 2005

\begin{abstract}
Polyelectrolyte multilayers are now a well established concept with numerous potential applications in particular as biomaterial coatings. To timely control the biological activity of cells in contact with a substrate, multicompartment films made of different polyelectrolyte multilayers deposited sequentially on the solid substrate constitute a promising new approach. In a first paper (Langmuir 2004, 20, 7298) we showed that such multicompartment films can be designed by alternating exponentially growing polyelectrolyte multilayers acting as reservoirs and linearly growing ones acting as barriers. In the present study, we first demonstrate however that these barriers composed of synthetic polyelectrolytes are not degraded despite the presence of phagocytic cells. We propose an alternative approach where exponentially growing poly(L-lysine)/hyaluronic acid (PLL/HA) multilayers, used as reservoirs, are alternated with biodegradable polymer layers consisting in poly(lactic-co-glycolic acid) (PLGA) and acting as barriers for PLL chains that diffuse within the PLL/HA reservoirs. We first show that these PLGA layers can be deposited alternatively with PLL/HA multilayers leading to polyelectrolyte multilayer/hydrolyzable polymeric layer films and acting as a reservoirs/barriers system. Bone marrow cells seeded on these films ending by a PLL/HA reservoir rapidly degrade it and internalize the PLL chains confined in this reservoir. Then the cells degraded locally the PLGA barrier and internalize the PLL localized in a lower (PLL/HA) compartment after 5 days of seeding. By changing the thickness of the PLGA layer, we hope to be able to tune the time delay of degradation. Such mixed architectures made of polyelectrolyte multilayers and hydrolyzable polymeric layers could act as coatings allowing us to induce a time scheduled cascade of biological activities. We are currently working on the use of comparable films with compartments filled by proteins or peptides and in which the degradation of the barriers results from a hydrolysis over tunable time scales.
\end{abstract}

\section{Introduction}

The alternate deposition of polyanions and polycations on a charged substrate leads to the continuous buildup of a film called a polyelectrolyte multilayer. These polyelectrolyte films constitute a very promising tool to modify the properties of solid substrates. ${ }^{1,2}$ It can also allow the construction of semipermeable membranes or filtration devices and the design of biomaterial coatings which constitute a major field of applications. ${ }^{3-5}$ To confer biological activities to multilayered films, one can incorporate peptides, proteins or even $\operatorname{drugs}^{6}$ and maintain

* Corresponding author. Phone: 333902430 61. Fax: 33390 2433 79. E-mail: philippe.lavalle@odonto-ulp.u-strasbg.fr.

$\dagger$ INSERM.

$\ddagger$ Université Louis Pasteur.

$\S$ CNRS, UMR7563.

"Université Henri Pointcaré.

$\perp$ Université d'Evreux.

\# CNRS, UPR22.

(1) Decher, G.; Hong, J. D. Ber. Bunsen-Ges. Phys. Chem. 1991, 95, 1430 .

(2) Decher, G. Science 1997, 277, 1232-1237.

(3) Krasemann, L.; Toutianoush, A.; Tieke, B. J. Membrane Sci. 2001 181, 221-228.

(4) Rmaile, H. H.; Schlenoff, J. B. J. Am. Chem. Soc. 2003, 125, 66026603.

(5) Miller, M. D.; Bruening, M. L. Langmuir 2004, 20, 11545-11551.

(6) Benkirane-Jessel, N.; Schwinté, P.; Falvey, P.; Darcy, R.; Haïkel, Y.; Schaaf, P.; Voegel, J.-C.; Ogier, J. Adv. Funct. Mater. 2004, 14, 174-182. their native structures. ${ }^{7-10}$ Following this scheme, films with anti-inflammatory or antimicrobial properties were recently constructed. ${ }^{6,10,11}$ The validity of the concept consisting in the buildup of functional films is now well established. We focus now our work on the modulation of the intensity and the kinetics of the cellular response when cells are seeded on these films. A first step in this direction was recently performed by adjusting the total number of polyelectrolyte layers covering the bioactive molecule layer. ${ }^{9}$ In this latter case, the films were composed of polyamino acids which allowed monocytic cells to degrade the multilayer and to reach the underlying bioactive molecules. These films thus do not act by releasing the active compounds but rather by allowing cells to come in contact with the active compounds. This strategy seems very powerful for biological applications in the field of surface treatment of implants located in a septic environment where anti-inflammatory properties are required.

(7) Caruso, F.; Niikura, K.; Furlong, D. N.; Okahata, Y. Langmuir 1997, 13, 3427-3433.

(8) Chluba, J.; Voegel, J.-C.; Decher, G.; Erbacher, P.; Schaaf, P.; Ogier, J. Biomacromolecules 2001, 2, 800-805.

(9) Jessel, N.; Atalar, F.; Lavalle, P.; Mutterer, J.; Decher, G.; Schaaf, P.; Voegel, J.-C.; Ogier, J. Adv. Mater. 2003, 15, 692-695.

(10) Jessel, N.; Lavalle, P.; Meyer, F.; Audouin, F.; Frisch, B.; Schaaf, P.; Ogier, J.; Decher, G.; Voegel, J.-C. Adv. Mater. 2004, 16, 15071511.

(11) Boulmedais, F.; Frisch, B.; Etienne, O.; Lavalle, P.; Picart, C.; Ogier, J.; Voegel, J.-C.; Schaaf, P.; Egles, C. Biomaterials 2004, 25, 2003-2011. 
A further step toward time activity control was recently achieved by embedding active proteins under multilayers constituted by polyelectrolyte blends containing various proportions of degradable and nondegradable polyelectrolytes. ${ }^{12}$ Based on such a strategy, monocytic cells exhibited specific responses with a time course which was tuned from 1 to $6 \mathrm{~h}$ depending on the film structure and composition.

The concept needs now to be further improved in two directions: (i) it is desirable to "multifunctionalize" such films by embedding different bioactive compounds acting in a sequential way. This is in particular needed in tissue engineering where various growth factors should be incorporated in the films to confer specific cellular activity in a sequential way. (ii) One should be able to tune the time response of the different biological activities over time delays ranging from a few hours to several weeks. Different devices such as hydrogels, nanocapsules, or polymeric membranes were designed to release drugs in given time delays and at a predetermined concentration. ${ }^{13-15}$ However, most of these drug delivery systems are selfsupporting-based materials and are not appropriate for biomaterial coatings. Polyelectrolyte multilayers, which do not act as drug delivery devices in this study, could be a proper way to design biologically active systems on prosthesis surfaces to guide for example tissue regeneration around the new implanted material. A strategy to produce coatings with time controlled activity could be to assemble multicompartment films, each compartment acting as a reservoir for various biomolecules, separated by barriers that avoid diffusion of biomolecules. The degradation of the barriers with time could allow a sequential contact of the cells anchored on the film with the active compounds and thus a sequential and time scheduled biological activity.

A first step toward such multicompartment films was achieved recently by alternating exponentially growing multilayers made of poly(L-lysine) (PLL) and hyaluronic acid (HA) and linearly growing films made of poly(allylamine) (PAH) and poly(styrene sulfonate) (PSS). ${ }^{16}$ Exponentially growing films were essentially obtained with systems composed of natural polyelectrolytes such as polysaccharides and polyamino acids. ${ }^{17-19}$ These films are less structured and are highly hydrated compared to linearly growing films composed of synthetic polyelectrolytes such as (PAH/PSS). At least one of the polyelectrolytes constituting the exponentially growing film can diffuse in the whole architecture during each bilayer deposition step. This was first shown for PLL chains in PLL/HA multilayer films: PLL chains are able to diffuse through the film, whereas HA chains remain located in their deposition positions. ${ }^{20}$ The compartments consisted

(14) Benkirane-Jessel, N.; Lavalle, P.; Hübsch, E.; Holl, V.; Senger B.; Haïkel, Y.; Voegel, J.-C.; Ogier, J.; Schaaf, P. Adv. Funct. Mater. 2005, 15, 648-654.

(15) Grayson, A. C. R.; Choi, I. S.; Tyler, B. M.; Wang, P. P.; Brem, H.; Cima, M. J.; Langer, R. Nat. Mater. 2003, 2, 767-772.

(16) Shchukin, D. G.; Patel, A. A.; Sukhorukov, G. B.; Lvov, Y. M. J. Am. Chem. Soc. 2004, 126, 3374-3375.

(17) Radt, B.; Smith, T. A.; Caruso, F. Adv. Mater. 2004, 16, 2184-+. (18) Garza, J. M.; Schaaf, P.; Muller, S.; Ball, V.; Stoltz, J. F.; Voegel, J.-C.; Lavalle, P. Langmuir 2004, 20, 7298-7302.

(19) Picart, C.; Lavalle, P.; Hubert, P.; Cuisinier, F. J. G.; Decher, G.; Schaaf, P.; Voegel, J.-C. Langmuir 2001, 17, 7414-7424.

(20) Lavalle, P.; Picart, C.; Mutterer, J.; Gergely, C.; Reiss, H.; Voegel, J.-C.; Senger, B.; Schaaf, P. J. Phys. Chem. B 2004, 108, 636-648.

(21) Richert, L.; Lavalle, P.; Payan, E.; Zheng, X. S.; Prestwich, G. D.; Stoltz, J. F.; Schaaf, P.; Voegel, J.-C.; Picart, C. Langmuir 2004, 20 448-458.

(22) Picart, C.; Mutterer, J.; Richert, L.; Luo, Y.; Prestwich, G. D.; Schaaf, P.; Voegel, J.-C.; Lavalle, P. Proc. Natl. Acad. Sci. U.S.A. 2002, 99, 12531-12535. of exponentially growing PLL/HA multilayers in which PLL chains could diffuse. These compartments were delimited by barriers composed of PAH/PSS multilayers (30 bilayers). Such barriers separated two compartments and prevented the diffusion of PLL chains from one compartment to the neighboring one. In another recent study, polyelectrolyte multilayers were covered with a wax layer to avoid the noncontrolled diffusion of water, ions, or drugs from multilayers to the bulk. ${ }^{21}$ Wood et al. described the buildup of multilayer films composed of a degradable poly $(\alpha$-amino ester $)$ with various biomolecules and tuned the deconstruction kinetics by adjusting $\mathrm{pH}$ values of the surrounding buffer. ${ }^{22}$

We present here a new way to build multifunctionalized films with timely scheduled biological activity namely by alternating exponentially growing polypeptide/polysaccharide multilayers with degradable polyester layers. The multilayers, which in our case will consist in PLL/HA films, will act as reservoirs. They are able to contain for example specific peptides or proteins. ${ }^{8,10}$ The polyester layers will be made of poly(lactic-co-glycolic acid) (PLGA) and act as barriers able to be degraded without the need of external stimuli. Our first goal will consist in checking that these PLGA films can be alternatively deposited with (PLL/HA) multilayers to form a multicompartment film. A specific method will be necessary since the PLL/HA multilayers are entirely built in aqueous solutions and PLGA is dissolved in chloroform. To demonstrate the validity of our concept, we will fill our multilayer compartments with fluorescently labeled PLL (PLL ${ }^{\text {FITC }}$ or PLL ${ }^{\text {Rho }}$ ) chains that act as markers. Bone marrow cells will be grown on such multicompartment films, and the gradual contact of the cells with the upper and lower compartments of the film will be followed versus time. We focus our study on bone marrow cells due to future applications for implants in contact with bone tissue. Time scales for film degradation will be of the order of a week for the polymers used in the present work and will be chosen for experimental convenience. Strategies to further tune these time scales will be discussed.

\section{Experimental Section}

Preparation of Polyelectrolyte and Polymer Solutions. Poly(L-lysine) (PLL, $\left.M_{\mathrm{w}}=5.7 \times 10^{4} \mathrm{Da}\right)$ and poly(D,L-lactic-coglycolic acid) copolymer ratio 50:50 (PLGA, $M_{\mathrm{w}}=4 \times 10^{4}-7.5$ $\times 10^{4} \mathrm{Da}$ ) were purchased from Sigma (St. Quentin Fallavier, France). Hyaluronic acid (HA, $M_{\mathrm{w}}=4.0 \times 10^{5} \mathrm{Da}$ ) was obtained from BioIberica (Barcelona, Spain). Polyelectrolyte solutions (1 $\mathrm{mg} \cdot \mathrm{mL}^{-1}$ ) were prepared by dissolution of the adequate amounts of polyelectrolytes in $0.15 \mathrm{M} \mathrm{NaCl}$ solution, $\mathrm{pH}=5.9$. PLGA has been dissolved in chloroform at $10 \mathrm{mg} \cdot \mathrm{mL}^{-1}$.

Fluorescently Labeled Polyelectrolytes. Fluorescein isothiocyanate labeled poly(L-lysine) (PLL ${ }^{\text {FITC }}, M_{\mathrm{w}}=5.0 \times 10^{4}$ Da) was obtained from Sigma (St. Quentin Fallavier, France). Rhodamine B (Invitrogen, Cergy Pontoise, France) was coupled to PLL as previously described. ${ }^{23}$ An appropriate amount of PLL $\left(1 \mathrm{mg} \cdot \mathrm{mL}^{-1}\right)$ was dissolved in a $\mathrm{Na}_{2} \mathrm{CO}_{3}$ solution $(0.1 \mathrm{M}, \mathrm{pH}=$ 8.5). Rhodamine (Rho) at $2 \mathrm{mg} \cdot \mathrm{mL}^{-1}$ was dissolved in DMSO (dimethylsulfoxyde). We used a ratio of $1 \mathrm{mg}$ of rhodamine for $50 \mathrm{mg}$ of PLL. The solutions were gently mixed at room temperature during $2 \mathrm{~h}$. PLL ${ }^{\text {Rho }}$ was purified by dialysis during 3 days, and then the absence of free rhodamine in the solution was checked by UV spectroscopy.

Buildup of Polyelectrolyte Multilayers. The multilayers were built with an automatized dipping robot (Riegler \& Kirstein

(23) Glinel, K.; Prevot, M.; Krustev, R.; Sukhorukov, G. B.; Jonas, A. M.; Mohwald, H. Langmuir 2004, 20, 4898-4902.

(24) Wood, K. C.; Boedicker, J. Q.; Lynn, D. M.; Hammond, P. T. Langmuir 2005, 21, 1603-1609.

(25) Hermanson, G. T. In Bioconjugate techniques; Hermanson, G. T., Ed.; Academic Press: San Diego, CA, 1996; pp 169-176. 
GmbH, Berlin, Germany) on silica slides. The slides were first dipped in a PLL solution (polycation) for $10 \mathrm{~min}$. Then, a rinsing step was performed by dipping the substrates for $10 \mathrm{~min}$ in 0.15 $\mathrm{M} \mathrm{NaCl}$ solution. The polyanion (HA) was then deposited in the same manner. The buildup process was pursued by the alternated deposition of PLL and HA. After deposition of $\mathrm{n}$ bilayers, the film will be denoted (PLL/HA)

Polymer Deposition. We used a spray bottle purchased from Carl Roth (Lauterbourg, France) and a spray nozzle from Lindal (Briey, France) for polymer deposition. The bottle was filled with air using a manual pump to maintain the inside pressure. The volume sprayed was calculated in order to get the desired thickness $(2 \mathrm{~mL}$ for a thickness of about $1 \mu \mathrm{m})$. PLGA solution was sprayed $(1 \mathrm{~mL} / \mathrm{min})$ over the hydrated multilayered (PLL/ $\mathrm{HA})_{n}$ film in which the last layer was constituted by PLLFITC The spray nozzle was positioned at $150 \mathrm{~mm}$ from the substrate with multilayers held vertically. The spraying cone was about three times larger than the substrate. No solution was collected at the bottom of the substrate due to the weak flow of the spray and to the rapid evaporation of the solvent during PLGA deposition. There was also no PLGA gradient measured through the substrate. Then, we constructed a multilayered (PLL/HA) film on the PLGA film following a method similar to the one previously described.

Confocal Laser Scanning Microscopy (CLSM). CLSM observations were carried out with a Zeiss LSM 510 microscope using a $\times 40 / 1.4$ oil immersion objective and with $0.4 \mu \mathrm{m}$ z-section intervals. FITC fluorescence was detected after excitation at 488 $\mathrm{nm}$ with cutoff dichroic mirror $488 \mathrm{~nm}$ and emission band-pass filter 505-530 $\mathrm{nm}$ (green). Rhodamine fluorescence was detected after excitation at $543 \mathrm{~nm}$, dichroic mirror $543 \mathrm{~nm}$, and emission long pass filter $585 \mathrm{~nm}$ (red). All of the experiments were performed in liquid conditions.

Confocal Raman Spectroscopy. Raman measurements were carried out by using a confocal Raman microscope similar to the system described by Schuster et al. ${ }^{24}$ It is composed of a Raman spectrometer (LabRam HR by Jobin-Yvon Horiba with a 600 lines/mm grating) coupled to a microscope (model BX41, Olympus) with an $x y z$ mapping stage via optical fibers. The excitation of Raman scattering was operating with a heliumneon laser at a wavelength of $632.8 \mathrm{~nm}$. The laser beam was focused on the layer by means of a $\times 100$ microscope objective. A confocal pinhole of $100 \mu \mathrm{m}$ diameter before the entrance slit rejects the Raman signal from out of focus planes. This enables a spatial resolution within the range $1-2 \mu \mathrm{m}$ which minimizes the background of the quartz carrier slides. Raman spectra of the layers with good signal-to-noise ratio were recorded with an integration time of 5-20 s.

Primary Bone Marrow Cells Isolation and Growth. Murine bone marrow cells were isolated from femurs 6- to 12wk-old mice and cultivated $\left(10^{6} / \mathrm{mL}\right.$ ) for $3 \mathrm{~h}$ in DMEM (Dulbelcco's modified eagle medium) supplemented with $2 \mathrm{mM}$ L-glutamine and antibiotics (all from Life Technologies, Paisley, U.K.). After resuspension in fresh medium, the bone marrow cells were plated in 24-well microculture plates at a density of $10^{5}$ cells/well in DMEM on multilayer films with various architectures. During confocal observations, cells were maintained in medium and after imaging were replaced in the incubator.

\section{Results and Discussion}

We first test bone marrow cells deposited on a film constituted of one compartment containing PLL chains fluorescently labeled and a (PAH/PSS) barrier adsorbed on the top. The bone marrow cell population is composed of various cells and in particular of monocytic cells characterized by their great phagocytosis capacity. Previous studies demonstrated the ability of these cells to degrade multilayers made of poly(L-lysine) and poly(Lglutamic acid) and to internalize fluorescently labeled polyelectrolytes. ${ }^{9,10,12}$ Observation of the (PLL/HA) $)_{20} /$ $\mathrm{PLL}^{\text {FITC}} / \mathrm{HA} /(\mathrm{PAH} / \mathrm{PSS})_{30} / \mathrm{PLL}$ film (with $\mathrm{PLL}^{\text {FITC }}$ for fluo-

(26) Schuster, K. C.; Urlaub, E.; Gapes, J. R. J. Microbiol. Methods 2000, 42, 29-38.
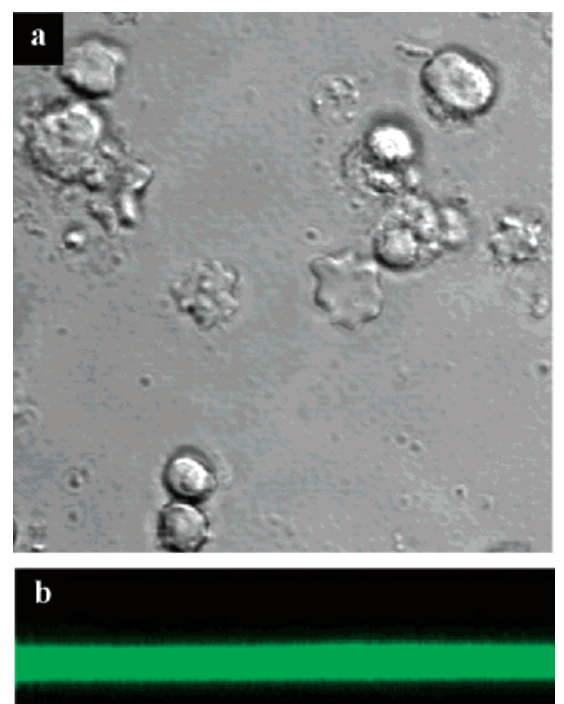

Figure 1. Observation by confocal laser scanning microscopy of bone marrow cells after $17 \mathrm{~h}$ of contact on (PLL/HA $)_{20} / \mathrm{PLL}^{\mathrm{FITC}} /$ $\mathrm{HA} /(\mathrm{PAH} / \mathrm{PSS})_{30} / \mathrm{PLL}$ film. (a) $(x, y)$ image in the bright field channel and green channel of a plane located on the top of the film. Image size is $48 \times 48 \mu \mathrm{m}^{2}$. (b) $(x, z)$ image of a film section (green channel) crossing some area containing cells. Image size is $48 \times 12.50 \mu \mathrm{m}^{2}$.

rescein isothiocyanate labeled PLL) by confocal microscopy reveals the presence of a $2.8 \mu \mathrm{m}$ section that appears entirely green due to the PLL ${ }^{\text {FITC }}$ diffusion through the PLL/HA section (Figure 1b).

Images of this system were taken after $17 \mathrm{~h}$ of contact between the cells and the surface. Whereas some cells adhere readily on the film, they remain uncolored (Figure 1 , panels a and b) and no internalization of PLLFITC is observed. The film seems also to remain unaltered and neither holes nor degradation can be visualized (Figure 1b). As we will see, cells that interact with the fluorescently labeled PLL chains present a green cytoplasm under confocal microscopy due to PLL ${ }^{\text {FITC }}$ internalization. This, thus, proves (i) that the cells do not come in contact with PLL ${ }^{\text {FITC }}$ located in the films and (ii) that the (PAH/PSS) $)_{30}$ multilayer acts as a nondegradable barrier for at least 17 $\mathrm{h}$ of contact with the bone marrow cells.

To create a barrier that can be degraded with time, we replaced, on top of a (PLL/HA $)_{20} / \mathrm{PLL}^{\text {FITC }}$ multilayer, the $(\mathrm{PAH} / \mathrm{PSS})_{30}$ barrier by a poly(lactic-co-glycolic acid) (PLGA) layer. This well-known biocompatible and biodegradable polymer is dissolved in chloroform. Usually PLGA films are obtained by solvent casting. To minimize the contact between chloroform and multilayers, we developed an alternative method where PLGA dissolved in chloroform was sprayed onto the multilayer. The volumes of chloroform used in the spray method are low and most of the chloroform deposited with PLGA is evaporated within a few seconds. However, we checked the stability of (PLL/HA $)_{30} / \mathrm{PLL}^{\mathrm{FITC}}$ multilayers after $3 \mathrm{~h}$ of immersion in a chloroform solution. No degradation or change in thickness was observed when imaged by confocal microscopy.

The thickness of the PLGA layers designed in this study generally ranges from 2 to $4 \mu \mathrm{m}$. We first observed with AFM (atomic force microscope) that the PLGA layer is homogeneous and determination of the mean roughness deduced from $10 \times 10 \mu \mathrm{m}^{2}$ images is equal to $16.9 \pm 3.8$ $\mathrm{nm}$. To promote cellular adhesion, PLL was adsorbed on top of the ending PLGA film. The film constituted by (PLL/ $\mathrm{HA})_{20} / \mathrm{PLL}^{\mathrm{FITC}} / \mathrm{PLGA} / \mathrm{PLL}$ was then brought in contact with bone marrow cells. After $17 \mathrm{~h}$ of incubation, the 

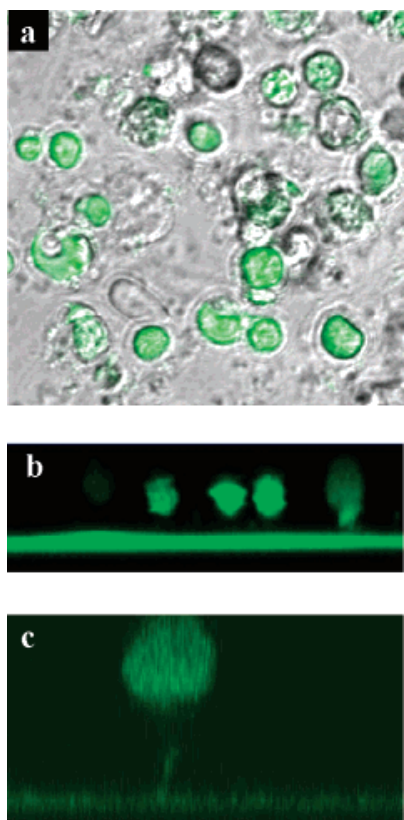

Figure 2. Observation by confocal laser scanning microscopy of bone marrow cells after $17 \mathrm{~h}$ of contact on (PLL/HA) $)_{20} / \mathrm{PLL}$ FITC PLGA/PLL film. (a) $(x, y)$ image in the bright field channel and green channel of a plane located on the top of the film. Image size is $48 \times 48 \mu \mathrm{m}^{2}$. (b) $(x, z)$ image of a film section (green channel) crossing some area containing cells. Image size is 48 $\times 16.40 \mu \mathrm{m}^{2}$. (c) $(x, z)$ image of a film section (green channel) crossing a cell and showing the pseudopod formation through the PLGA layer. Image size is $24.8 \times 13 \mu \mathrm{m}^{2}$.

system was imaged by confocal microscopy (Figure 2 , panels $a$ and $b)$. A section of the film $(2.8 \mu \mathrm{m}$ thick $)$ appears entirely green corresponding probably to the (PLL/HA) ${ }_{20}-$ PLLFITC multilayer. Most of the deposited bone marrow cells show internal green fluorescence. A closer look on the image section reveals that the fluorescent cells are not directly in contact with the green film section but are deposited on a nonlabeled layer (between 2 and $3 \mu \mathrm{m}$ thick) corresponding most probably to the PLGA layer. Moreover, the cells/PLL ${ }^{\text {FITC }}$ contacts seem to be the consequence of a pseudopod formation through the PLGA layer (see Figure 2c). Such pseudopods were already observed with monocytic cells deposited on top of a PGA/PLL multilayer into which an active protein was embedded.9,12 It was demonstrated that the biological activity was due to the local degradation of the multilayers induced by the cells. This degradation certainly takes place at the same location where the pseudopods are formed. Local degradation of the films induced by the cells and pseudopod formation should thus also be at the origin of the degradation of the PLGA barrier. This degradation results from enzymatic activity or a local decrease of the $\mathrm{pH}$ induced by the cells. On the basis of previous studies, it is known that the high molecular weight PLGA used in the present study $\left(M_{\mathrm{w}}=\right.$ $\left.4 \times 10^{4}-7.5 \times 10^{4} \mathrm{Da}\right)$ and deposited as a $2-4 \mu \mathrm{m}$ thick film could not be subject to significant spontaneous hydrolytic degradation after a few hours. ${ }^{13}$ Control experiment performed by deposition of bone marrow cells on a film built only with (PLL/HA) $)_{20}-$ PLL $^{\text {FITC }}$ show that after $1 \mathrm{~h}$ the cells appear already green.

PLL/HA multilayer compartments could then be further deposited on top of the PLGA film. Figure 3 a shows a film buildup with two (PLL/HA) $)_{30}$ compartments separated by one PLGA barrier. The last deposited layer in each compartment buildup was always realized with fluorescently labeled PLL chains. We used PLLFITC to label in green one compartment and PLL ${ }^{\text {Rho }}$ to label the other
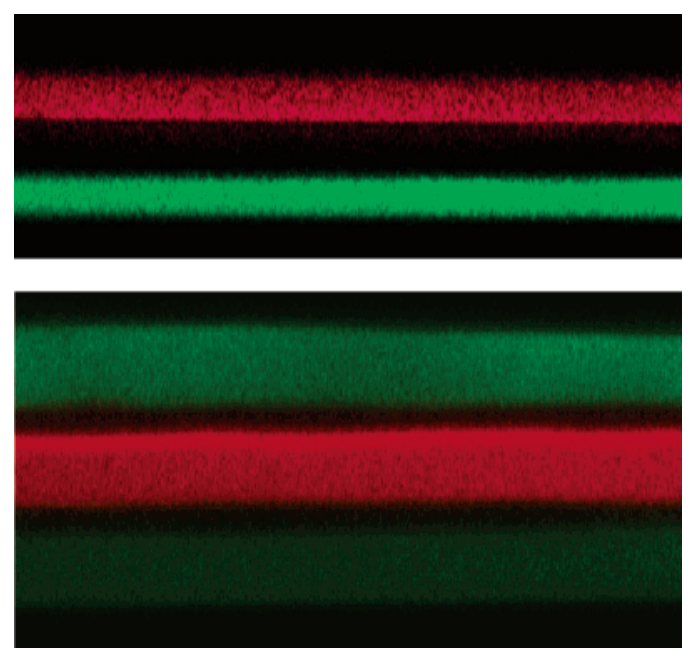

Figure 3. Observation by confocal laser scanning microscopy of multicompartment films. (a) (PLL/HA) 30 $_{30} / \mathrm{PLL}^{\mathrm{FITC}} / \mathrm{PLGA} / \mathrm{PLL} /$ $\mathrm{HA})_{30} / \mathrm{PLL}^{\mathrm{Rho}}$ film section $(x, z$, green and red channels). Image size is $76.8 \times 28.5 \mu \mathrm{m}^{2}$. (b) (PLL/HA) ${ }_{30} / \mathrm{PLL}^{\text {FITC}} / \mathrm{PLGA} /(\mathrm{PLL} /$ $\mathrm{HA})_{30} / \mathrm{PLL}^{\text {Rho}} / \mathrm{PLGA} /(\mathrm{PLL} / \mathrm{HA})_{30} / \mathrm{PLL}^{\mathrm{FITC}}$ film section $(x, z$, green channel). Image size is $76.8 \times 40.6 \mu \mathrm{m}^{2}$.

compartment in red. The (PLL/HA) $)_{30} / \mathrm{PLL}^{\mathrm{FITC}} / \mathrm{PLGA} / \mathrm{PLL} /$ $\mathrm{HA})_{30} / \mathrm{PLL}^{\text {Rho }}$ films are always smooth at the micrometer scale when visualized by confocal microscopy. One further observes that when one compartment was labeled with FITC and the next compartment with rhodamine, the two compartments each keep their respective color, and the PLGA film appears always dark. The thickness of each $(\mathrm{PLL} / \mathrm{HA})_{30} / \mathrm{PLL}$ compartment is also comparable $(5.3 \mu \mathrm{m})$. This clearly indicates that the PLGA films act as impermeable barriers toward PLL chains avoiding an exponential growth of the second compartment in the continuity of the exponential growth of the first one. This was expected due to the strong hydrophobicity of PLGA which does not allow a crossing by hydrophilic polymers. A storage of one month of such a film in the medium does not change the architecture as visualized by confocal microscopy indicating that PLGA is not sufficiently hydrolyzed during this time delay to become permeable (data not shown).

We also tested the buildup of a film constituted of two PLGA barriers and three (PLL/HA $)_{30} / \mathrm{PLL}$ compartments (Figure 3b). A (PLL/HA) ${ }_{30} / \mathrm{PLL}^{\mathrm{FITC}} / \mathrm{PLGA} /(\mathrm{PLL} / \mathrm{HA})_{30} /$ $\mathrm{PLL}^{\text {Rho}} / \mathrm{PLGA} /(\mathrm{PLL} / \mathrm{HA})_{30} / \mathrm{PLL}^{\text {FITC }}$ film section imaged by CLSM shows two green bands corresponding to the (PLL/ $\mathrm{HA})_{30} / \mathrm{PLL}^{\mathrm{FITC}}$ compartments and one red band corresponding to the (PLL/HA) $)_{30} / \mathrm{PLL}^{\text {Rho }}$ compartment separated by two dark lines corresponding to the PLGA layers. The spray deposition method of PLGA instead of a more conventional one like solvent casting allows the buildup of a homogeneous PLGA layer without any deterioration of the previously deposited PLGA layer.

A film constituted by two compartments separated by a PLGA layer was also analyzed by confocal Raman microspectroscopy ${ }^{25}$ (Figure 4). We followed the vertical distribution of PLL/HA and PLGA across the film section by measuring the intensities of two characteristic peaks common to PLL and HA (at $~ 945$ and at $\sim 1645 \mathrm{~cm}^{-1}$ ) and the intensity of a characteristic band of PLGA (at 1770 $\left.\mathrm{cm}^{-1}\right) .{ }^{26}$ The two compartment structure with the PLGA

(27) Volodkin, D. V.; Petrov, A. I.; Prevot, M.; Sukhorukov, G. B. Langmuir 2004, 20, 3398-3406.

(28) van Apeldoorn, A. A.; van Manen, H. J.; Bezemer, J. M.; de Bruijn, J. D.; van Blitterswijk, C. A.; Otto, C. J. Am. Chem. Soc. 2004, 126, 13226-13227. 


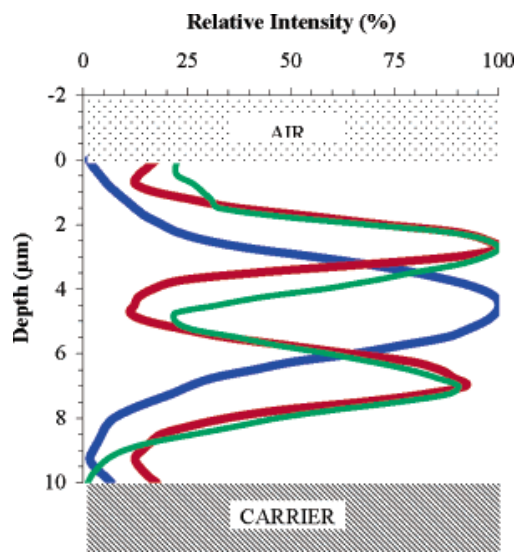

Figure 4. Depth profile of the intensities of Raman bands characteristic of PLL and HA (green, $940-950 \mathrm{~cm}^{-1}$; red, 1640$1650 \mathrm{~cm}^{-1}$ ) and characteristic of PLGA (blue, $1770 \mathrm{~cm}^{-1}$ ) obtained by confocal Raman microspectroscopy across a (PLL/ $\mathrm{HA})_{30} / \mathrm{PLL} / \mathrm{PLGA} /(\mathrm{PLL} / \mathrm{HA})_{30} / \mathrm{PLL}$ film. For each band, the intensity is normalized by attributing the value $100 \%$ to the maximum intensity.

barrier clearly emerges. However, due to the spatial resolution of the technique (of the order of $1-2 \mu \mathrm{m}$ ) the PLL/HA and PLGA compartments seem to overlap. This is due to the fact that the signal coming from out-of-focus planes cannot be totally avoided, even with a small confocal pinhole.

The main goal behind the buildup of multicompartment films is to apply a coating on a substrate that induces a cascade of timely scheduled events. Bone marrow cells were thus grown on such multicompartment films to follow the sequential degradation of the different parts of the architecture. We brought these cells in contact with the two-compartment film where the upper compartment was labeled with PLL ${ }^{\text {Rho }}$ and the lower compartment with PLL $^{\text {FITC }}$ (same as film imaged in Figure 3a). Figure 5 shows the evolution of the CLSM images taken on this system with time. Figure 5, panels a-c, were taken after $1 \mathrm{~h}$ of contact between the cells and the film. Most of the bone marrow cells have already internalized red labeled PLL located in the upper compartment. No green labeled PLL is internalized by the cells after $1 \mathrm{~h}$ despite the presence of a lower compartment with these labeled chains. The cells and the film appeared qualitatively similar when observed after $24 \mathrm{~h}$ and 2 days (data not shown). After 5 days of contact, the cells start to internalize green PLL FITC (Figure 5, panels $\mathrm{d}$ and f). These green and red colors are located in the cells, the upper compartment remaining red elsewhere. This confirms the conclusion drawn previously that the PLGA barrier is probably only locally degraded by the cells and not by spontaneous hydrolysis. The high molecular weight of the PLGA used in the present study avoids a spontaneous hydrolysis of the chains after few days of contact with the medium. ${ }^{13}$ This was also confirmed by the absence of degradation of the same films after 2 months of storage in an incubator without any cells but in the presence of medium.

After 10 days of contact, almost all of the cells were both red and green indicating that the degradation process had still progressed. The upper film part exhibited also both the red and green colors. The green fluorescence internalized by the cells was more pronounced after 10 days of contact compared to 5 days. Red fluorescence was also slightly detected in the lower compartment. It is not clearly seen in Figure $5 \mathrm{~g}$ due to the high intensity of the green color, but it can be visualized by selecting only the red channel. The PLL ${ }^{\text {FITC }}$ of the lower compartment could

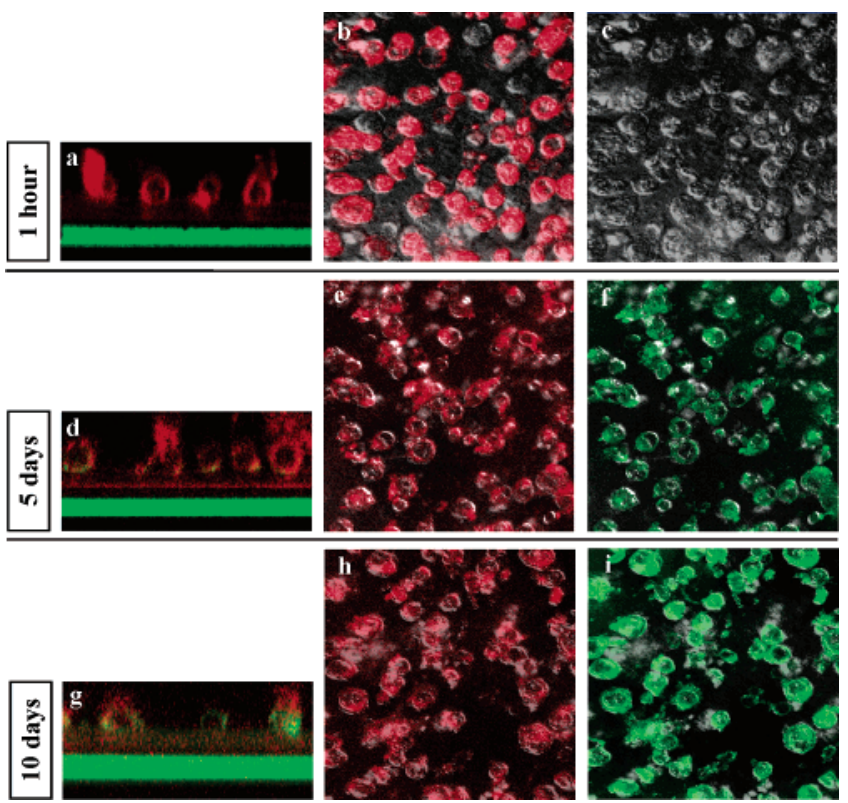

Figure 5. Observation by confocal laser scanning microscopy of a multicompartment film composed of (PLL/HA) $)_{30} / \mathrm{PLL}^{\text {FITC }}$ $\mathrm{PLGA} /(\mathrm{PLL} / \mathrm{HA})_{30} / \mathrm{PLL}^{\text {Rho }}$. Panels a, $\mathrm{d}$, and $\mathrm{g}$ correspond to film sections $(x, z$ sections in red and green channels, image sizes are $76.8 \times 28.6 \mu \mathrm{m}^{2}$ ). Panels $\mathrm{b}, \mathrm{e}$, and h correspond to $x, y$ sections in the bright field and red channels (image sizes are $76.8 \times 76.8$ $\mu \mathrm{m}^{2}$ ). Panels $\mathrm{c}, \mathrm{f}$, and and i correspond to $x, y$ sections in the bright field and green channels (image size are $76.8 \times 76.8$ $\mu \mathrm{m}^{2}$ ). Film is observed after $1 \mathrm{~h}$ (panels a-c), 5 days (panels $\mathrm{d}-\mathrm{f}$ ), and after 10 days (panels $\mathrm{h}$ and i) of contact with bone marrow cells.

thus enter in contact with the upper compartment probably due to local film degradation induced by the cells. $\mathrm{PLL}^{\text {Rho }}$ from the upper compartment reached the lower one following an identical mechanism.

\section{Conclusion}

In summary, we describe in this paper multicompartment films made of different polyelectrolyte multilayers and degradable polymers alternatively deposited on a solid substrate. In a previous paper, ${ }^{16}$ we showed that such films can be obtained by alternating exponentially growing films acting as reservoirs and linearly growing ones acting as barriers. However, these barriers are not degradable. In the present study, we proposed an alternative approach where exponentially growing multilayers, used as reservoirs, are alternated with biodegradable polymer poly(lactic-co-glycolic acid) (PLGA) films, acting as barriers. We first showed that polyelectrolyte multilayers can be deposited alternatively with polymer layers of PLGA leading to films composed of reservoirs and barriers. Bone marrow cells seeded on these films ending by a PLL/HA reservoir rapidly degrade it and internalize the PLL chains confined in this reservoir. Then the cells degraded locally the PLGA barrier and, after 5 days, internalize the PLL localized in a lower (PLL/HA) compartment. By changing the thickness of the PLGA layer, we hope to be able to tune this time delay. The cells probably mediate then the transfer of polyelectrolytes from one compartment to the other. These films will thus be able to act as a coating allowing us to induce a time scheduled cascade of biological activity. We are currently working on the use of comparable films with compartments filled by proteins or peptides in which the degradation of the barriers results from a hydrolysis over time scales of a few days. This would constitute another way to mediate a cellular signalization. 
Acknowledgment. This work was supported by the ACI "Nanosciences 2004" from the Ministère de la Recherche et des Nouvelles Technologies (Project NR204). J.M.G is indebted to CONACyT (Consejo Nacional de Ciencia y Tecnologia, México) for financial support. We thank Laurent Lambert (Lindal Group, Briey, France) for his assistance with spray deposition methods, and Jérôme Mutterer (Institut de Biologie Moléculaire des
Plantes, CNRS/ULP, Strasbourg, France) for his help with the CLSM. The CLSM platform used in this study was co-financed by the Région Alsace, the Université Louis Pasteur, and the Association pour la Recherche sur le Cancer. We also thank Karim Benmlih for his technical assistance with the automatic dipping robot.

LA051465B 